\title{
Who Says Yes or No? Models of Ethical and Safety Oversight for Student-Led Political Violence Research
}

Kristine Eck, Uppsala University

Dara Kay Cohen, Harvard Kennedy School

ABSTRACT The ethical risks inherent in student research on political violence that involve human participants are myriad. Undergraduate and master's students face constraints that are different than those for many doctoral students and faculty researchers, and it is the responsibility of educators and academic institutions to ensure that students engage in ethical practices and to mitigate risks. This article focuses on formal mechanisms of oversight. Drawing on discussions with colleagues across the globe, we describe how institutions can design oversight mechanisms to manage student research. We present five distinct models for how ethical oversight of student research is provided in academic programs around the world, considering the costs and benefits of each model. The article concludes that whereas the creation of oversight systems can seem daunting, it is useful to start small-indeed, moving from no oversight to some oversight is a significant improvement. Programs and academic units then can build on these early efforts, experiment with other systems, and eventually develop a system that is adapted to an institution through iterative improvements based on student and faculty experiences.

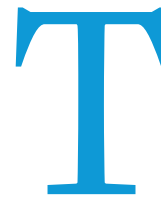

he ethical and safety risks inherent in student research on political violence, often involving vulnerable people and sensitive topics and conducted in unstable contexts, are myriad (Mitchell 2013). Undergraduate and master's students who are conducting original human subjects research as part of an undergraduate honor thesis or master's dissertation face significant constraints that are different than those of many doctoral students and faculty researchers. These constraints include little or no training in necessary methods or research ethics, few (if any) formal mechanisms of ethical oversight, short time horizons, clustering in over-researched areas, and the unlikely prospect of publication or dissemination of research results (Eck and Cohen

Kristine Eck (Di) is associate professor of peace and conflict research at Uppsala University. She can be reached at kristine.eck@pcr.uu.se.

Dara Kay Cohen (D) is professor of public policy at Harvard Kennedy School. She can be reached at dara_cohen@hks.harvard.edu.
2021). These problems expose numerous ethical and safety dilemmas related to the weighing of risks and benefits to the research participants, research team, and researchers themselves; obtaining free and informed consent; and engaging in best practices such as reciprocity with research participants. Scholars and faculty members who advise these students argue that it is the responsibility of educators and academic institutions to require that students engage in ethical practices and to mitigate risks, including a shift away from fieldwork-based research projects. A core recommendation is to discourage human subjects research on political violence by undergraduate and master's students without adequate training, preparation, resources, and supervision (Eck and Cohen 2021).

Despite these serious concerns, there are strong incentives for institutions to continue to offer, enable, and fund student research on politically sensitive topics with human participants. Consequently, the tide of student research projects is unlikely to abate in the foreseeable future. The widespread perception that employers value field experience-especially in risky or otherwise challenging 
settings-has led to a demand from students for opportunities to obtain that experience during their degree program, a demand to which universities have financial incentives to cater (Mitchell 2013; Parkinson 2019). Students also articulate a desire to complement classroom learning with "real-world" experience, a sentiment shared by faculty who believe that human subjects research is a valuable skill that students should acquire. However, on a global scale, organized, robust systems of ethics oversight often do not exist for student research. Given this reality, scholars have proposed ways that individual faculty members who serve as advisors and mentors can mitigate some of the risks, mainly through redirecting students to other sources of data and evidence (Eck and Cohen 2021). However, placing the burden of ethics review on an individual advisor is only one solution.

\section{MODELS OF OVERSIGHT}

This section describes five models of ethical oversight based on a series of discussions with faculty members at different types of institutions around the world. ${ }^{2}$ The discussion is driven by the core concern that students should be subject to a process of oversight that ensures the protection of research participants with whom they interact. That said, when discussing the advantages and disadvantages of the different models, we consider factors that not only affect the ethics of the project (e.g., the contextual knowledge needed to assess risk) but also those that impact the feasibility of a model (e.g., administrative costs). ${ }^{3}$ We do so because each institution must adopt or tailor ethics oversight systems to its own particular context; what is optimal at one university may not be practical at another.

\section{On a global scale, organized, robust systems student research.}

How universities should ensure ethical student-led research is a broad issue that encompasses many possible components, including classroom training. This article focuses on the absence of formal mechanisms of ethics and student-research safety oversight, which has long been a blind spot for many programs. While faculty and doctoral students can (and may be required to) access university ethics review boards such as Institutional Review Boards (IRBs) in the United States, many master's and undergraduate students in the United States and around the world cannot. One reason for this lack of access is based on student status; in some countries, only projects by faculty and doctoral students are eligible for review. In addition, ethics review boards may not review certain forms of evidence collection, such as those in service of a real-world client. In the United States, IRBs may consider this type of work to be "consulting" rather than "research," thereby viewing these projects as beyond their mandate. In some places, formal oversight mechanisms for even ethically complex social science research are not required or are entirely absent for even faculty members and doctoral students. ${ }^{1}$ More broadly, the functioning and coverage of ethics review boards often are problematic; scholars have reported that review boards do not ensure adequate protection of participants (Michelson 2016). However, although scholars are increasingly aware of these problems for advanced researchers, research by novice students has not been considered extensively.

This article presents examples of how individuals and institutions can design oversight mechanisms to manage student research with the goal of mitigating ethics and safety problems. We present five distinct models for ethical oversight of student research and discuss the advantages and disadvantages of each model. Our purpose is not to advocate for a single model; institutions must adapt to the context in which they operate. We emphasize, however, the importance of training in order to foster the development of an ethical compass to guide student-led research. Our goals for this article are to inspire (1) an exchange of ideas about this often-overlooked issue, in which faculty members around the world can learn from one another about what works; and (2) institutions that lack ethical oversight for student research to consider initiating formalized processes.

\section{The Mentor Model}

In the mentor model, ethical oversight for each project is delegated to a student's faculty advisor. Our discussions with colleagues suggest that this may be the most common global form of ethical review. In some cases, this review is informal, potentially consisting of only a conversation with the student about ethical best practices. In other cases, it may be more formalized. For example, the academic department may provide instructions or guidelines for the advisors' review process, emphasizing particularly important ethical concerns such as the protection of vulnerable people. In addition, departments may collect and track data on where students are traveling and which resources they may have available (e.g., funding, local connections, and language skills). This latter version-a combination of an individual advisor with simple coordinating mechanisms and loose support from a broader institution-is a good place to begin for institutions that want to move beyond the mentor model.

The mentor model has significant benefits in terms of the low administrative burden of reviewing student projects. Student ethics oversight is built into the general advising process; therefore, mentors are already familiar with their students, their interests, and their skills. Students also receive individualized attention and support in developing research plans, including consideration about the safety and well-being of the research team. Finally, the system lacks a bureaucracy, so changes to research plans can happen swiftly without the long waiting times of ethics review boards.

However, these benefits must be weighed against possible costs. The mentor model introduces the possibility of general ethical principles being applied inconsistently across a program. In addition, faculty advisors do not always have direct experience in a specific country or topic-or they may not have any experience conducting field research. As such, it can be challenging even for best-intentioned advisors to give guidance or accurate advice on local ethics. Ideally, faculty advisors would seek advice from other experts familiar with a particular context, but this can place a significant burden on advisors.

Finally, without a systematic overview of the student body as a whole, there is no way for a program to track where students 
are traveling. This is important from an ethical perspective in terms of both student safety and avoiding over-research of particular communities or countries. Whereas some universities may require all affiliates to register with a travel office when conducting university business abroad, others do not. Without these resources and in cases of crisis, students may be entirely reliant on their advisor-and any personal travel insurance they have purchased-to assist them in an emergency.

\section{The IRB Model}

In the IRB model, undergraduate and master's student research is reviewed by an external committee of experts under a system governed by national regulations and university standards. This model provides the advantages of systematic oversight of under- and experience when evaluating the risks for a project submitted by experienced faculty-who arguably may be able to tolerate and manage more risk-versus novice student researchers. Finally, IRBs may interpret pertinent regulations such that there are significant loopholes for the least-experienced student applicants. For example, ethics review boards may not evaluate any projects by undergraduate student researchers or, in the case of clientbased student projects, IRBs may determine that these projects do not meet the federal definition of "research" and decline to review them. However, in a system that primarily relies on IRBs for review, if the IRB decides a class of student research is ineligible, it again is unclear who should oversee these projects. Under these conditions, oversight often reverts to the ad hoc version of the mentor model.

\section{To the extent that these broad reservations about IRBs are valid concerns, they are doubly so for student researchers who lack the experience to compensate for IRB shortcomings.}

graduate and master's student projects analogous to that of doctoral students and faculty members. The required paperwork induces students to consider the risks and benefits of their proposed research project for the research participants within the context of a transparent set of rules. The IRB model relies on experienced professionals, thereby creating a valuable system of institutional memory built on the cumulative experience of regularly evaluating research projects.

Administratively, the costs are not borne directly by an individual department but instead are centralized at the IRB. This can become prohibitively time-consuming for the IRB if there are numerous student projects that must be evaluated in a short period. IRB processes can operate slowly, with a month (and typically more) in processing time; depending on the progression of a program, IRB delays may prohibit students from executing their project on the schedule required for their academic program. In some countries (e.g., Sweden), an individual researcher must pay a fee for an IRB evaluation, which may be unaffordable for some students. In other countries, academic units pay the IRB on a per-project basis, thereby making the provision of an ethics review a significant budgetary burden.

IRBs and ethics review boards are not a panacea, however. Many scholars note that IRBs often serve the legal interests of the university first and foremost (Blee and Currier 2011; CroninFurman and Lake 2018). In addition, the purview of IRBs is research subjects, not the research team, student safety, or issues of research design. ${ }^{4}$ Furthermore, although projects may be reviewed by subject matter and disciplinary experts, ethics review boards may lack the expertise needed to evaluate risks in developing-world environments, which is particularly problematic in the context of political violence. Finally, scholars argue that the ethical requirements of the IRB are "a floor, not a ceiling" (Aufderheide 2016), which is further emphasized in the new American Political Science Association (APSA) Principles and Guidance for Human Subjects Research. ${ }^{5}$

To the extent that these broad reservations about IRBs are valid concerns, they are doubly so for student researchers who lack the experience to compensate for IRB shortcomings. In particular, IRBs may not consider the differences in research qualifications

\section{Committee of Experts Model}

In the committee of experts model (hereafter committee model), a department creates oversight at the level of the academic unit (often a department) composed of its own faculty members. This model has several advantages: it facilitates a more systematic application of ethical principles from case to case relative to other models (e.g., the mentor model) and generates institutional memory. As with the IRB model, the level of institutionalization ensures that students are provided with transparent rules and procedures. Both the application procedures and the criteria adopted by the committee for ethics approval can be tailored to the environment and therefore are more flexible than IRB rules. As a result, the purview of the committee model can be broader and oversight can include consideration of risks for both students and their research team. An institution can develop its own bespoke guidelines for student applications that place greater emphasis on a careful analysis of the context in which the project will take place and on the discipline in which the research will be conducted. The APSA Principles provide a set of overarching principles and a discussion of the applications that can serve as core guidance for a committee of experts. ${ }^{6}$ Faculty members also may be more familiar with the risks involved with sensitive conflict contexts than IRBs, whose members may not understand particular countries or research methods.

The committee model also entails costs. Primarily, this process can be administratively burdensome for an institution and faculty members who comprise the committee. Although the freedom to set a high ethical standard in the committee model may allow for the rigorous consideration of student projects, it also means that the committee must achieve consensus on where to set that standard. The ethics of human subjects research-particularly in the context of political violence-often are difficult to assess, and even experienced experts may have vastly different opinions about what is or is not acceptable. ${ }^{7}$ Grappling with these issues can generate fruitful debates among faculty members but also can induce stress and conflict among colleagues. Because the committee creates its own set of rules, it must be able to self-regulate internal disagreements. The necessity of applying comparable decisions across cases implies that the faculty involved can find 
common ground across their heterogeneous notions about ethical standards.

Furthermore, even professional IRBs have been shown to apply regulations inconsistently across institutions (Babb, Birk, and Carfagna 2017). Committees of experts may be even more prone to subjective, uninformed, or inconsistent rulings regarding the ethics and safety of student-led research. This inconsistency may lead to either halting student projects that could have proceeded, or-potentially more troubling-allowing student projects to proceed that should not. Committees can develop mechanisms to ensure consistent and informed rulings, for example, by relying on the same basic principles every year (e.g., the APSA Principles), relying on precedents over time, building on the expertise of faculty members with interest in or experience with research ethics and design, and consulting outside experts for particularly challenging or contentious cases.

\section{The Russian Doll Model}

The Russian doll model is a hybrid of several other models involving different levels of oversight that are embedded within one another; therefore, this is only a brief description of the model's advantages and disadvantages. A typical version of this model entails a student first submitting a brief research proposal to the department. If the proposal meets certain criteria that determine it to be higher risk thereby warranting additional consideration, then it must be evaluated in detail by another body-a centralized IRB, a local committee of experts, or both.

The Russian doll model allows a department to have a comprehensive overview of all student projects and to create a bureaucratic record of the types of research in which students are engaged. The rules are transparent, allowing the same standards to be applied to all students. By making a first cut, a department can reduce some transaction costs by omitting unproblematic cases and focusing resources on those projects that require careful consideration. This also has the advantage of engaging multiple decision makers, reducing variability in individual faculty members' assessments.

However, this model also has disadvantages. It does not ameliorate the drawbacks associated with IRBs or committees of experts (depending on what the second evaluating body is) and therefore is best understood as a modified version of one of those two systems.

\section{The Local Collaborator Model}

In the local collaborator model, students are allowed to conduct human subjects research only in conjunction with an approved local partner, typically as part of an internship. In this model, students must receive buy-in from a local collaborator who hosts them in order for the project to move forward. This model may be combined with another model (e.g., IRB or committee of experts); however, in some cases, the buy-in from a local collaborator is a de facto substitute for other forms of ethical review.

Collaboration with a local partner entails numerous benefits that can support ethical research. Local collaborators are best placed to know about sensitive contexts and relevant actors and how they change on the ground. In areas that have experienced political violence, the context can shift dramatically from day to day and with it the safety of participants and the research team. Local collaborators are better equipped than novice students to evaluate the possible fallout of a changing political landscape.
Local collaborators typically are invested in maintaining good relations with research participants and are more likely to veto potentially harmful interventions. Local collaborators typically also center considerations about the safety and well-being of the research team.

These benefits are conditional on the merits and organizational goals of the local collaborator. Local organizations can be profit-driven or biased or may fail to act in a student's or a community's best interests. They also may feel pressured to compromise their ethics when hosting students from prestigious and affluent foreign universities (Cronin-Furman and Lake 2018; Eriksson Baaz and Utas 2019). This places a burden on a student's academic institution to vet local organizations before embedding students.

This type of collaboration may not be viable for practical reasons. Depending on the structure of an educational program, it may not be feasible for students to be abroad for the long duration that this type of combined internship/research project requires. Long periods abroad also require more funding than shorter fieldwork stints and may be prohibitively costly for students and programs. The advising process might suffer from students' prolonged absences, and conflicts of interest may arise between the academic aims that must be met and how local collaborators would prefer that students spend their time. Finally, this model covers only a portion of the type of human subjects research in which students engage-namely, those involving fieldwork. Many students want to conduct interviews or focus groups in their home country or use online surveys or survey experiments. A system that is solely reliant on local collaborator buy-in for oversight would not encompass these projects.

Table 1 summarizes the advantages and disadvantages of each model, highlighting the value of each oversight system and the administrative burdens that each places on faculty mentors and programs.

\section{CONCLUSION}

This article presents five distinct models for providing ethical oversight of student research. A lack of ethical-oversight processes is a major lacuna in how academic programs and faculty members train and mentor students embarking on complex human subjects research. By discussing a broad array of solutions, we offer various ways to introduce oversight mechanisms to ensure more robust processes and more ethical research with less risk of harm.

In conversations with colleagues, we found that there frequently were no oversight systems, particularly for master's and undergraduate students. Our colleagues' descriptions of the origin stories of different oversight systems at their institution often echoed one another. New faculty members were surprised to discover the lack of ethical oversight of student projects and, together with like-minded colleagues, developed some type of institutional response. We were struck by how isolated these processes were; our colleagues expressed frustration at the lack of dialogue in the discipline that could guide them. This article is a direct response to those experiences and an attempt to fill this gap.

Evaluating research ethics is a subjective enterprise and faculty engaged in oversight need support. All of the models highlightedperhaps especially the mentor model-should coordinate a way for advisors to discuss their experiences with one another. Increased dialogue can help institutions and the discipline to harmonize 
Table 1

Models for Ethical Oversight of Student-Led Research

\begin{tabular}{|c|c|c|}
\hline Model & Advantages & Disadvantages \\
\hline Mentor & $\begin{array}{l}\text { - low bureaucracy } \\
\text { - quick adaptation } \\
\text { - can expand scope of coverage }\end{array}$ & $\begin{array}{l}\text { - dependent on mentor expertise } \\
\text { - uneven application of ethics principles across student projects } \\
\text { - no broad picture of students' global footprint }\end{array}$ \\
\hline IRB & $\begin{array}{l}\text { - systematic and transparent, institutional memory } \\
\text { - professional system } \\
\text { - no costs to faculty }\end{array}$ & $\begin{array}{l}\text { - possible delays and fees } \\
\text { - scope of coverage limited to human subjects } \\
\text { - lack of fine-grained contextual knowledge }\end{array}$ \\
\hline $\begin{array}{l}\text { Committee } \\
\text { of Experts }\end{array}$ & $\begin{array}{l}\text { - systematic and transparent, institutional memory } \\
\text { - can design bespoke guidelines } \\
\text { - staffed by faculty with contextual expertise }\end{array}$ & $\begin{array}{l}\text { - administratively costly } \\
\text { - potentially divisive among faculty members } \\
\text { - no formal systems of appeals for students }\end{array}$ \\
\hline $\begin{array}{l}\text { Russian Doll } \\
\text { (Hybrid) }\end{array}$ & $\begin{array}{l}\text { - systematic and transparent, institutional memory } \\
\text { - broad picture of students' global footprint } \\
\text { - reduced transaction costs } \\
\text { - quick adaptation } \\
\text { - can expand scope of coverage }\end{array}$ & - replicates disadvantages of systems that it embeds \\
\hline $\begin{array}{l}\text { Local } \\
\text { Collaborator }\end{array}$ & - highest levels of contextual expertise & $\begin{array}{l}\text { - may not be feasible } \\
\text { - inapplicable for non-fieldwork-based projects } \\
\text { - may result in uneven application of ethics principles across student projects } \\
\text { - local collaborators may be biased or otherwise incapable of ensuring } \\
\text { research ethics and safety, particularly if collaborators were parties to } \\
\text { political violence }\end{array}$ \\
\hline
\end{tabular}

standards regarding student research ethics. The APSA Principles (i.e., Principle 12(a)) specifically cite the "shared responsibility" of "mentors, advisors, dissertation committee members, and instructors [to] help students and subordinates identify and address ethical issues related to research." Ethical guidelines for advising student-led research, produced by relevant sections of students to consider research ethics, which they might not do otherwise, and they provide evaluation and feedback from an experienced third party. Monitoring and mentoring student researchers when they are engaged in human subjects research are overlooked but necessary aspects of ensuring that the discipline does no harm. However, oversight alone is insufficient: both

\section{It is useful to start small-indeed, moving from no oversight to some oversight is a significant improvement.}

APSA or the International Studies Association, may be a useful next step. These five oversight models demonstrate one possibility for how to put this critical principle into practice.

There is no single best solution. Different programs operate under different conditions, and the appropriate oversight depends on who the students are, what is expected of their work, and what type of studies they are conducting with which types of resources, support, and constraints. Likewise, institutions must consider staffing and other bureaucratic transaction costs in assessing how to best design oversight in the context of their system. Ethics oversight is only one pillar of creating an environment that ensures responsible student ethics. Programs also should ensure that students receive adequate training before developing their own projects; the fact that $\mathrm{PhD}$ training does not include significant ethics training and only a fraction of programs provides qualitative methods training (Emmons and Moravcsik 2019) suggests that this is likely to be equally lacking-if not more acute-for undergraduate and master's students. ${ }^{8}$

Given the limitations of formal oversight processes and the fact that the ethical landscape often can shift while a researcher is in the field, training that focuses on cultivating an ethical and situational awareness is central to ensuring that student researchers "do no harm." Ethics-oversight processes prompt training and oversight are important pedagogic tools that faculty should use to ensure ethical student research within programs.

Although the creation of oversight systems can seem daunting, it is useful to start small-indeed, moving from no oversight to some oversight is a significant improvement. Programs and academic units then can build on these early efforts, experiment with other systems, and eventually develop a system that is adapted to an institution through iterative improvements based on student and faculty experiences. It is critical for educators to complement these oversight processes with student ethics and safety training anchored in the robust, ongoing dialogue within the discipline. -

\section{NOTES}

1. As is the case in many countries, ethics review may be required for medical studies but not social science research (e.g., Haiti).

2. To gather information on ways that student research receives ethical review and oversight, we authored a public call for engagement that was posted on a widely read blog (Eck and Cohen 2019) and shared on social media. We also reached out to colleagues in countries in several regions of the world in different types of programs. Finally, we talked to members of an IRB in the United States. This discussion is not intended to be a comprehensive survey of the universe of master's and undergraduate programs but rather an illustrative snapshot of various systems. Based on an email exchange with the Committee on the Use of Human Subjects at Harvard University regarding the requirements for IRB review, we 
determined that these informal conversations did not meet the threshold for regulatory research.

3. We leave unanswered the question of legal risk and who assumes it because this can vary across locations and contexts; however, we acknowledge that adhering to laws and university regulations are crucial criteria.

4. Research design can become an ethical issue-for example, if a survey study is underpowered such that participants are exposed to risk but researchers are unlikely to learn anything from the sample.

5. APSA Principle 11(b) states: "Researchers should understand that...approval by a review or permitting body is not always sufficient for ethical research. The requirements for ethical research may go beyond what...IRBs....and regulatory bodies may require."

6. See https://connect.apsanet.org/hsr/principles-and-guidance.

7. One example of disagreement among faculty drawn from our conversations with colleagues is related to the conditions under which researchers' deception in the context of survey experiments is acceptable. Scholars have shown that field experiments are controversial both within the academy and among the public (i.e., the potential research pool). See Desposato's (2018) study of scholars and the public on field experiments that use deception but do not obtain informed consent.

8. The provision of ethics instruction is another "shared responsibility" in the APSA Principles. One possible solution is Collaborative Institutional Training Initiative (CITI) training, a standard online training program funded by the US Department of Health and Human Services. However, the CITI training is focused on protections of human subjects and does not address other risks of harm to individual researchers, the research team, or the broader community. As a result, CITI training is at best only a partial solution.

\section{REFERENCES}

Aufderheide, Patricia. 2016. "Does This Have to Go Through the IRB?" Chronicle of Higher Education, August 17. www.chronicle.com/article/does-this-have-to-gothrough-the-irb.
Babb, Sarah, Lara Birk, and Luka Carfagna. 2017. "Standard Bearers: Qualitative Sociologists' Experiences with IRB Regulation.” The American Sociologist 48 (1): 86-102.

Blee, Kathleen, and Ashley Currier. 2011. "Ethics Beyond the IRB: An Introductory Essay." Qualitative Sociology 34 (3): 401-13.

Cronin-Furman, Kate, and Milli Lake. 2018. "Ethics Abroad: Fieldwork in Fragile and Violent Contexts." PS: Political Science \& Politics 51 (3): 607-14.

Desposato, Scott. 2018. "Subjects' and Scholars' Views on the Ethics of Political Science Field Experiments." Perspectives on Politics 16 (3): 739-50.

Eck, Kristine, and Dara Kay Cohen. 2019. "Ethics of Student Research on Political Violence: Starting a Dialogue." Political Violence at a Glance. https:// politicalviolenceataglance.org/2019/08/29/ethics-of-student-research-onpolitical-violence-starting-a-dialogue.

Eck, Kristine, and Dara Kay Cohen. 2021. "Time for a Change: The Ethics of StudentLed Human Subjects Research on Political Violence." Third World Quarterly $42(4): 855-66$.

Emmons, Cassandra V., and Andrew M. Moravcsik. 2019. "Graduate Qualitative Methods Training in Political Science: A Disciplinary Crisis." PS: Political Science $\mathcal{E}$ Politics 53 (2): 258-64.

Eriksson Baaz, Maria, and Mats Utas. 2019. "Exploring the Backstage: Methodological and Ethical Issues Surrounding the Role of Research Brokers in Insecure Zones." Civil Wars 21 (2): 157-78.

Michelson, Melissa R. 2016. "The Risk of Over-Reliance on the Institutional Review Board: An Approved Project Is Not Always an Ethical Project." PS: Political Science \& Politics 49 (2): 299-303.

Mitchell, Audra. 2013. “Escaping the 'Field Trap': Exploitation and the Global Politics of Educational Fieldwork in 'Conflict Zones."' Third World Quarterly 34 (7): 1247-64.

Parkinson, Sarah E. 2019. "Humanitarian Crisis Research as Intervention." Middle East Report 290:29-37. https://merip.org/2019/o7/humanitarian-crisis-research-asintervention. 